\title{
Time-trends and correlates of obesity in Czech adolescents in relation to family socioeconomic status over a 16-year study period (2002-2018)
}

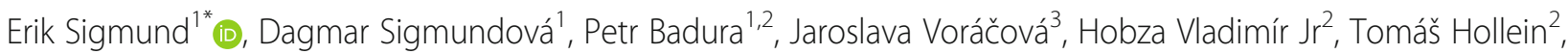
Jan Pavelka², Zuzana Pưžová ${ }^{2}$ and Michal Kalman²

\begin{abstract}
Background: The main objective of the study is to analyse the changes in the prevalence of obesity among Czech adolescents between 2002 and 2018 with regard to the socioeconomic status (SES) of adolescents' families and to find SES-separated correlates of adolescents' obesity in 2018.

Methods: A nationally representative sample of 29,879 adolescents (49.6\% of them boys) aged 10.5-16.5 years was drawn from the Health Behaviour in School-aged Children cross-sectional, self-reported questionnaire surveys conducted in 2002, 2006, 2010, 2014, and 2018 in Czechia. Chi-square $\left(x^{2}\right)$ tests were performed to assess the changes in the prevalence of obesity in both genders and all SES categories of adolescents between 2002 and 2018, and SES category-related differences in the prevalence of obesity in 2018 separately for boys and girls. A series of multiple stepwise logistic regression (backward elimination) analyses were used to reveal obesity correlates separately for SES categories of adolescents.

Results: Across the quadrennial surveys from 2002 to 2018, we observed a clear increase in the prevalence of obesity in all SES categories of adolescents, which was most striking $(p<0.05)$ in adolescents with low SES (boys: + $7.5 \%$ points (p.p.); girls +2.4 p.p.). When all the survey cycles were compared, the highest prevalence of obesity was evident in the low-SES adolescents in 2018, both in girls (5.1\%) and boys (12.0\%). Regardless of the adolescent SES category, the lower odds of obesity were significantly $(p<0.05)$ associated with regular vigorous physical activity (PA), participation in organized sport, and daily consumption of sweets. In addition, at least 60 min of moderate-tovigorous PA significantly reduced the odds of obesity in adolescents of low and high SES categories.

Conclusions: An unreasonable increase in the prevalence of obesity in adolescents with low SES highlights the need to prevent obesity in adolescents with a low-SES background. Additionally, significantly higher odds of obesity in 11- and 13-year-old adolescents from low-SES families, compared with their peers aged 15, indicated an expectable rise in obesity in older low-SES adolescents in the near future.
\end{abstract}

Keywords: Obesity, Physical activity, Socioeconomic status, Health behaviour of school-aged children study

\footnotetext{
*Correspondence: erik.sigmund@upol.cz

${ }^{1}$ Faculty of Physical Culture, Institute of Active Lifestyle, Palacký University

Olomouc, 77111 Olomouc, Czech Republic

Full list of author information is available at the end of the article
}

(c) The Author(s). 2020 Open Access This article is distributed under the terms of the Creative Commons Attribution 4.0 International License (http://creativecommons.org/licenses/by/4.0/), which permits unrestricted use, distribution, and reproduction in any medium, provided you give appropriate credit to the original author(s) and the source, provide a link to the Creative Commons license, and indicate if changes were made. The Creative Commons Public Domain Dedication waiver (http://creativecommons.org/publicdomain/zero/1.0/) applies to the data made available in this article, unless otherwise stated. 


\section{Background}

The epidemic of obesity in every segment of the population is a serious public health problem in the highincome as well as low- and middle-income countries of the world [1-3]. The prevalence of obesity is generally lower but is increasing faster in low- and middle-income countries than in high-income countries $[4,5]$, but the evidence from, for example, the former Communist Bloc countries in Europe is still limited [6]. On the evidence of the existing prevalence and trend data [1, 7-9] and the epidemiological evidence linking obesity with longterm cardiovascular, metabolic, and other health consequences [10], it is necessary to describe obesity as a public health crisis with serious negative impacts on the quality of life of people and imposing a considerable burden on national health-care budgets $[11,12]$.

To simplify, obesity is the result of a long-term positive energy balance between food intake and expenditure, with its rate being mediated by the complex interaction of multiple behavioural, biological, and environmental factors [13-16]. Lifestyle behaviour is strongly associated with obesity in school-aged children, regardless of country or continent $[13,15,16]$. Everyday physical activity of moderate-to-vigorous intensity (MVPA) and longer sleep duration have been associated with lower odds of overweight or obesity in school-aged children [16], while shorter sleep duration and longer outside-of-school screen time (ST - watching television and playing video/computer games) have been associated with higher odds of obesity $[15,16]$. The consumption of sugar-sweetened beverages as an example of unhealthy food intake has been shown to be one of the key contributors to the risk of child overweight/obesity [17]. Although the consumption of sugar-sweetened beverages has declined over the last 15 years, it is still high among children and adolescents, with a negative impact on health - a higher incidence of obesity, insulin resistance, and dental caries [17]. Many of the energy balance-related behaviours in children and young people vary considerably with regard to the socio-economic status (SES) of their families $[6,16,18,19]$.

One of the major social determinants of child and adolescent obesity is the SES of their families [7, 9, 20]. Only a few of the trend-related publications that exist reveal a growing socioeconomic gradient in high-income countries - a stabilized or slight decreasing trend in the prevalence of obesity in children and adolescents from high-SES families, as opposed to a steady increase in the prevalence of obesity among their peers from low-SES families [7, 9,20]. Between 2003 and 2014, active participation in the Special Supplemental Nutrition Program for Women, Infants, and Children in Los Angeles [20] was first accompanied by an increase in childhood obesity (2003-2005), followed by a stagnation of obesity
(2005-2010), and then a final decline in childhood obesity (2010-2014), with significant differences between children from different SES backgrounds. In most years, the incidence of childhood obesity was highest in the families with the lowest SES [20]. Bann et al. [21] point to a diametric change in the relationship between SES and body weight in a longitudinal survey. In the cohorts before 2001, lower SES was associated with lower weight and inequalities did not differ systematically with age until the 2001 cohort, in which weight and BMI inequalities widened at older ages. Nevertheless, critical information gaps persist in relation to the impact of childhood and life course SES on obesity in low- and middle-income countries [22], as well as an analysis of the impact of health-related programmes on the prevalence of obesity regarding SES [5].

Low- and middle-income European countries (including the countries of Central and Southern Europe from the former Communist bloc) appear to tend to replicate the 'negative' health-related behaviour patterns - a decrease in MVPA, an increase in ST [6, 23, 24] - which had previously been reported in high-income countries [25]. The rapid increase in childhood and adolescent obesity in low- and middle-income countries underlines the fact that these countries have failed to learn from the development of obesity in high-income countries. Czechia is one of the most economically developed European countries in the former Communist bloc [26]. Since 2006, it has been implementing a number of national health-related and sports programmes (such as "The Olympic Flag of Versatility", "School Fruit and Vegetable Scheme ", and "School Milk Scheme") for children and adolescents, supported by the Ministry of Education, Youth, and Sports [27]. However, the effect of these programmes on the health and health-related behaviour of children and adolescents is not monitored and evaluated to an adequate extent.

The present study attempts to bridge the gap between the national health-related and sports programmes that have been implemented and the lack of evidence of their effectiveness in terms of their potential impact on the prevalence of obesity. Therefore, the main objective of the study is to analyse the changes in the prevalence of obesity among Czech adolescents between 2002 and 2018 with regard to the SES of adolescents' families and to find SES-separated correlates of adolescents' obesity in 2018.

\section{Methods}

Study design

This study is based on five cycles of the Czech "Health Behaviour in School-aged Children" (HBSC) cross-sectional study. The HBSC study is a World Health Organization (WHO) collaborative cross- 
national study conducted in 48 countries across Europe, North America, and Asia. The HBSC study focuses on the description of adolescents' health and health-related behaviours to inform policy makers, professionals, and practitioners to improve adolescents' lifestyle [28]. An international standardized questionnaire and research protocol were used across all the participating countries to ensure the consistency of survey instruments, data collection, and processing procedures $[28,29]$. As HBSC is a schoolbased survey, data is collected through selfcompletion questionnaires administered in the classroom. This study builds on methodology from a previously published work [18] and extends it by the most recent survey data and different analytical approach.

\section{Participants and data collection}

Nationally representative samples of Czech adolescents in the age range 10.5-16.49 years were recruited during the 2002 ( $n=4912 ; 47.7 \%$ boys), 2006 ( $n=4629 ; 50.4 \%$ boys), 2010 ( $n=4121 ; 48.7 \%$ boys $), 2014 \quad(n=4588$; $47.6 \%$ boys), and 2018 ( $n=11,629 ; 50.4 \%$ boys) school years by using multistage stratified designs, with census regions, ratio of primary vs. multi-year grammar schools, and grades as strata, with schools acting as the primary sampling units (Table 1). The school response rate among the survey cycles varied from 75 to $99 \%$ and the adolescent participants' response rate exceeded $80 \%$. The participating teenagers were predominantly white Caucasian (>96.5\%), which corresponds to the very homogeneous ethnic demography of the Czech Republic [32].

Trained researchers collected the data during a single morning lesson in the classroom using pen-and-paper questionnaires between 2002 and 2014 and in the IT classroom using online questionnaires in 2018. The participation of the adolescents in the quadrennial surveys was voluntary, and the respondents were assured of anonymity and the confidentiality of their responses. To ensure anonymity, the participants were instructed to put the questionnaire in an envelope, which they sealed and handed over to the researchers (2002-2014) after the survey was completed.

In 2018, during the online data collection, each participant received a unique application code to access a questionnaire from the researcher. The written consent of participants was obtained through the school management at all the schools involved in the survey. All the survey procedures for each data collection cycle were stored and can be downloaded from [33]. This study was approved by the Institutional Research Ethics Committee of the Faculty of Physical Culture, Palacký University Olomouc, with the reference No. 9/2016 on 4th March 2016.

Table 1 Descriptive characteristics of the samples, HBSC study, Czech Republic 2002-2018

\begin{tabular}{|c|c|c|c|c|c|c|c|c|c|c|}
\hline & 2002 & & 2006 & & 2010 & & 2014 & & $2018+$ & \\
\hline \multirow{3}{*}{$n=$} & Boys & Girls & Boys & Girls & Boys & Girls & Boys & Girls & Boys & Girls \\
\hline & $(2345)$ & $(2567)$ & $(2332)$ & $(2297)$ & (2008) & (2113) & (2183) & $(2405)$ & $(5856)$ & $(5773)$ \\
\hline & $\%$ & $\%$ & $\%$ & $\%$ & $\%$ & $\%$ & $\%$ & $\%$ & $\%$ & $\%$ \\
\hline \multicolumn{11}{|l|}{ Age category $^{\S}$} \\
\hline 11 years & 34.1 & 33.1 & 31.4 & 31.2 & 32.6 & 30.6 & 29.9 & 30.3 & 32.7 & 32.8 \\
\hline 13 years & 32.5 & 33.8 & 33.5 & 33.9 & 31.4 & 35.2 & 33.9 & 34.4 & 34.5 & 34.4 \\
\hline 15 years & 33.4 & 33.1 & 35.1 & 34.9 & 36.0 & 34.2 & 36.2 & 35.3 & 32.8 & 32.8 \\
\hline \multicolumn{11}{|l|}{ SES } \\
\hline Low & 34.2 & 40.5 & 25.7 & 30.3 & 13.1 & 17.0 & 32.4 & 34.4 & 23.7 & 27.2 \\
\hline Medium & 56.5 & 53.0 & 54.9 & 55.9 & 54.2 & 53.3 & 44.3 & 45.4 & 45.3 & 44.6 \\
\hline High & 9.3 & 6.5 & 19.4 & 13.8 & 32.7 & 29.7 & 23.3 & 20.2 & 31.0 & 28.2 \\
\hline \multicolumn{11}{|l|}{ Weight status* } \\
\hline Non-overweight & 81.6 & 91.7 & 77.9 & 83.8 & 73.7 & 88.1 & 74.8 & 87.9 & 73.3 & 84.7 \\
\hline $95 \% \mathrm{Cl}$ & $80.0-83.2$ & $90.6-92.7$ & $76.2-79.6$ & $82.3-85.3$ & $71.8-75.7$ & $86.7-89.5$ & $73.0-76.6$ & $86.6-89.2$ & $72.1-74.4$ & $83.8-85.7$ \\
\hline Overweight & 14.5 & 6.5 & 14.2 & 11.8 & 18.7 & 9.5 & 18.1 & 9.3 & 17.9 & 11.9 \\
\hline $95 \% \mathrm{Cl}$ & $13.1-16.0$ & $5.6-7.4$ & $12.8-15.6$ & $10.5-13.1$ & $17.0-20.4$ & $8.3-10.7$ & $16.5-19.7$ & $8.2-10.5$ & $16.9-19.0$ & $11.0-12.7$ \\
\hline Obesity & 3.9 & 1.8 & 7.9 & 4.4 & 7.6 & 2.4 & 7.1 & 2.8 & 8.8 & 3.4 \\
\hline $95 \% \mathrm{Cl}$ & $3.1-4.7$ & $1.3-2.3$ & $6.8-9.0$ & $3.6-5.3$ & $6.4-8.8$ & $1.7-3.1$ & $6.0-8.2$ & $2.1-3.5$ & $8.1-9.6$ & $2.9-3.9$ \\
\hline
\end{tabular}

${ }^{\S} 11$ years (13 years and 15 years) includes adolescents in the age range $10.5-12.49$ years (12.50-14.49 years and $14.50-16.49$ years); + in the 2018 data analyses, the weights for strata (administrative regions) were applied; SES socioeconomic status; ${ }^{*}$ obesity and overweight were represented by the $>97$ th percentile and 85th-97th percentile, respectively, on gender-specific Body Mass Index-for-age growth charts [30, 31]; Cl 95\% confidence interval 


\section{Survey items \\ Obesity}

The adolescents' self-reported actual body weight $(\mathrm{kg})$, body height $(\mathrm{cm})$, and chronological age were used to calculate the weight status of the participants. The Body Mass Index (BMI) was calculated as body weight (kg) divided by body height $(\mathrm{m})$ squared. Body weight status (non-overweight, overweight, obesity) was determined in accordance with the WHO's gender-specific BMI-forage growth charts [31]. Obesity and overweight were represented by the $>97$ th percentile and 85 th-97th percentile, respectively, on the gender-specific BMI-for-age growth charts $[30,31]$ (Table 1). The BMI calculated from self-reported body height and weight demonstrated good diagnostic ability to identify excessive body weight in children and adolescents compared with direct anthropometric measurements (sensitivity, specificity, positive and negative predictive values ranged from 0.83 to 0.98) [34]. Self-reported body height and weight show high agreement with the values measured in the laboratory (Pearson correlation $\mathrm{r}_{\text {HEIGHT }}=0.82-0.95 p<.001$; $\left.\mathrm{r}_{\text {WEIGHT }}=0.90-0.96 p<.001\right)$, thus making it possible to identify excessive body weight in children and adolescents in epidemiological studies substantially [34-36].

\section{Socioeconomic status}

Because of repeatedly detected gender and socioeconomically related differences in the prevalence of excessive body weight $[18,37]$ of adolescents, all the analyses were stratified according to the gender of the participants and family SES. An estimate of family SES was provided by the Family Affluence (FA) Scale. The FA scale comprised several simple-to-answer ageappropriate questions created to quantify material assets in the family [38, 39]. Between 2002 and 2010, four questions were included to determine FA: having one's own bedroom $(\mathrm{No}=0$; Yes $=1)$, number of computers (None $=0 ;$ One $=1$; Two $=2$; Three or more $=3$ ), car ownership (No =0; One $=1$; Two or more $=2)$, and family holidays in the past year $($ Never $=0$; Once $=1$; Twice $=2$; Three or more times $=3$ ) [38]. In 2014, an updated version of the FA scale was used to compensate for the changing social environment [23, 28]. Two new FA-related items - dishwasher ownership (No =0; Yes = 1) and number of bathrooms (None $=0$; One $=1$; Two $=$ 2 ; Three or more $=3$ ) were added to the existing FA scale. The response codes to these items were summed and treated as a composite sum score. For the analyses, three categories of SES ("low", "medium", and "high") were created from the composite sum score. Between 2002 and 2010 the SES categories correspond to tertiles of the sum score ("low" =0-3; "medium" = 4-6, "high" = 7-9) and in 2014 and 2018 as follows: "low" =0-6, "medium" =7-9, and "high" =10-13 [18]. High validity (kappa coefficient $0.41-0.74 ; 76.2-88.1$ agreement) and moderate reliability (Cronbach's $\alpha=0.58$ ) between children's and parents' responses on the FA scale-related items have been documented repeatedly [40-44]. Under the social and economic conditions of Czechia, the FA scale was validated with respect to the gross domestic product (Pearson correlation $\mathrm{r}=0.773 p<.001$ ) [45].

\section{Energy balance-related behaviours}

The energy balance-related behaviours covered physical activity patterns (daily MVPA, weekly vigorous physical activity (WVPA), and participation in organized sport), sedentary behaviour (daily entertainment screen time), dietary patterns (daily consumption of fruits, vegetables, sweets, and sweetened soft drinks; daily breakfast on school and weekend days, and frequency of fast food meals).

Among all the survey cycles MVPA was examined by a single question, 'Over the past seven days, on how many days were you physically active for a total of at least 60 minutes per day?' A definition of MVPA was provided as any activity that usually increases your heart rate and makes you get out of breath some of the time, with examples of activities that produce such an effect. The response categories were consistent among all the survey cycles and ranged from '0 days' to ' 7 days'. For the analyses of current MVPA recommendations ( $\geq 60$ min per day [46]) a dichotomous outcome variable was created. The weekly participation in WVPA was determined by the question 'How often do you usually exercise in your free time so much that you get out of breath or sweat?' with seven response categories: 'Every day', '4 to 6 times a week', '2 to 3 times a week', 'Once a week', 'Once a month', 'Less than once a month', and 'Never'. In line with existing precedents [47], the outcome variable for WVPA was dichotomized as follows: $\geq 4$ days of the week vs. less frequent WVPA. The assessment of selfreported MVPA and WVPA during the past seven days in adolescents was originally developed and validated against seven-day continuous measurement with an accelerometer $\left(\mathrm{r}_{\mathrm{MVPA}}=0.40 p<.01 ; \mathrm{r}_{\mathrm{WVPA}}=0.36 p<.01\right)$ [48]. A recent study supports the validity of self-reported past-seven-days MVPA $(\mathrm{r}=0.49 p<.01$ correlation with seven-day continuous monitoring with an Actigraph accelerometer) [49], with almost perfect test-retest stability of the MVPA item in Polish $(\mathrm{ICC}=0.98)$ and Chinese $(\mathrm{ICC}=0.82)$ 11-15-year-old adolescents $[50,51]$. The WVPA-related question in the HBSC questionnaire demonstrated moderate stability $(\mathrm{ICC}=0.68)$ [51].

Participation in organized sport was investigated using the question on involvement in organized activities (six activities including team sports, individual sports): 'In your free time, do you do any of these organized activities? We mean activities you do in a sports or other club or organization' with the dichotomous response 'yes'/'no' 
[52]. The participating adolescents were categorized as 'active' (involved in organized team and/or individual sport) or 'inactive' (not involved in any organized sport). The scale of participation in organized sport has an acceptable level of agreement $(\mathrm{ICC}=0.64)$, indicating good reliability [53].

In 2002, two items related to ST in free time were assessed. The adolescents were asked the following questions: 'About how many hours a day, in your free time, do you usually spend watching television (including DVDs and videos)?' and 'About how many hours a day, in your free time, do you usually spend using a computer (for playing games, emailing, chatting, or surfing on the internet)?' In all the other data collection cycles, the question related to computer use was subdivided into two questions to better reflect the changes in screenbased activities. The first sub-question, 'About how many hours a day, in your free time, do you usually spend using electronic devices such as computers, tablets (such as an iPad) or smartphones for other purposes, for example, homework, emailing, tweeting, Facebook, chatting, or surfing the internet?, represents the non-gaming part of computer use. The second sub-question, 'About how many hours a day, in your free time, do you usually spend playing games on a computer, games console, tablet (such as an iPad), smartphone, or other electronic device (not including moving or fitness games)?', represents the gaming part of computer use [54]. Each ST-related question was asked for weekdays and weekend days separately. For each ST-related question, the same response options were provided 'None at all', 'About half an hour a day', 'About 1 hour a day', 'About 2 hours a day', 'About 3 hours a day', 'About 4 hours a day', 'About 5 hours a day', 'About 6 hours a day', and 'About 7 or more hours a day'. The validity of self-reported STrelated questions for the past seven days has been proved in comparison with 7-day 24-h diaries both on weekdays $(\mathrm{r}=0.39-0.46, p<.001)$ and at weekends $(\mathrm{r}=$ 0.37-0.47, $p<.001)[55,56]$. At least 7 -day test-retest stability of the ST-related questions (computer use (PC) and television viewing (TV)) have been repeatedly verified among adolescents aged 11-15 for weekdays $\left(\mathrm{ICC}_{\mathrm{PC}}=0.33-0.82, \quad \mathrm{ICC}_{\mathrm{TV}}=0.54-0.72\right)$ and weekends $\left(\mathrm{ICC}_{\mathrm{PC}}=0.33-0.66, \mathrm{ICC}_{\mathrm{TV}}=0.58-0.68\right)[50,51,55,57]$. The daily ST outcome variable comprised the sum of three (two in 2002) ST-related questions. In accordance with previous ST-related studies [58, 59], the cutoff point for the dichotomization of daily ST was set at ' 2 or more hours daily' vs. 'less than 2 hours daily'. As part of the validated brief food frequency questionnaire, adolescents were asked: 'How many times a week do you consume fruit/vegetables/sweetened soft drinks/sweets?', with seven response categories: 'Never', 'Less than once a week', 'Once a week', 'Two to four times a week', 'Five to six times a week', 'Once a day', and 'More than once a day' and 'How often do you usually have breakfast (more than a glass of milk or fruit juice)?' with six response categories for weekdays ('Never', 'One day', 'Two days', 'Three days', 'Four days' and 'Five days'), and three for weekends ('Never', 'Only on one day', and 'On both days') [19]. In line with previous trend-related studies $[19,60]$ the response options were recorded into dichotomous outcome variables, 'daily' vs. 'less than daily'. The last question investigated the frequency of eating in fast food restaurants: 'How many times a month do you eat in fast food restaurants?', with seven response categories: 'Never', 'Rarely', 'Once a month', 'Two to three times a month', 'Once a week', 'Two to four days a week', and 'Five days a week or more'. The outcome variable for eating in fast food restaurants was dichotomized as follows: 'at least twice a month' vs. 'less often'.

\section{Sleep time}

Sleep time was calculated from the participants' reports of bedtimes and wake-up times separately for school days and weekends. Bedtimes were asked about by a single question, 'When do you usually go to bed if the next morning is a school day (weekend day)?' Self-reported alternatives for bedtimes ranged at half-hour intervals from 'at least $9 \mathrm{pm}$ ' to '2 am or later' for school days and 'at least $9 \mathrm{pm}$ ' to ' 4 am or later' for weekend days. Wake-up times were asked about as follows: 'When do you usually wake up on school (weekend) mornings? The response categories ranged at half-hour intervals from ' 5 am at the latest' to ' 8 am or later' for school days and '7 am at the latest' to ' $2 \mathrm{pm}$ or later' for weekends [61]. Finally, sleep time was calculated as the difference between bedtime and wake-up time, separately for weekdays and weekend days. The outcome variable for sleep time was categorized in relation to the age-related recommendation for hours of sleep [62] as follows: 'enough sleep' vs. 'not enough sleep' for school days and 'enough sleep', 'not enough sleep', and 'excessive sleep' for weekends. The sleep-related items demonstrated at least substantial reliability (ICC $=0.75 / 0.64$ for the usual bedtime on school days/weekends; ICC $=0.77$ for wake up on school days), especially for the item on when the participants wake up at weekends, for which the reliability is almost perfect $($ ICC $=0.83)[51]$.

\section{Data analysis}

All data processing and statistical analyses were performed in the Statistical Package for the Social Sciences (SPSS) for Windows v.22 software (IBM Corp. Released 2013. Armonk, NY, USA). Descriptive data are presented as percentages, including $95 \%$ confidence intervals (CI) in the case of weight status, for each survey cycle and gender separately. Chi-square $\left(\chi^{2}\right)$ tests were performed 
to assess trend-related differences in the prevalence of overweight/obesity in each gender and SES categories of adolescents between 2002 and 2018, and SES categoryrelated differences in the prevalence of overweight/obesity in 2018 separately for boys and girls. The chi-square $\left(\chi^{2}\right)$ tests were also used to analyse the differences in the proportion of participants involved in organized sports and engaging in WVPA in relation to SES categories of adolescents and to test the statistical significance of differences in the prevalence of obesity by adolescents' WVPA level, participation in organized sport, and frequency of consumption of sweets. A series of multiple stepwise logistic regression (backward elimination) analyses in the 2018 data collection were used to reveal obesity correlates separately for SES categories of adolescents. Finally, only statistically significant correlates of adolescent obesity will be presented. Given the larger sample, which represents the whole country and individual administrative regions, strata-specific weights were used for the 2018 data. The regression parameters were based on the odds ratio (OR) with a $95 \% \mathrm{CI}$. An alpha level of $5 \%$ was set for all the statistical procedures.

\section{Results}

\section{Changes in prevalence of obesity}

There is an evident increasing trend in the prevalence of obesity (Fig. 1) in adolescents of both genders from lowSES backgrounds between 2002 and 2018. A detailed overview of the prevalence of obesity (\%) in girls and boys in each SES category in each year of data collection, including confidence intervals, is presented in Table 2.
A significant increase in obesity between 2002 and 2018 was also uncovered in adolescents in the mediumSES category (Fig. 1). The 'up-stairs' effect in the prevalence of obesity (i.e. the sharp increase between 2002 and 2006 was replaced by stagnation/decline between 2006 and 2014, with a subsequent increase between 2014 and 2018) in the 2002-2018 period was typical for all SES categories of adolescents except for girls from the high-SES category. In addition, between 2014 and 2018 , there was apparently not only an increase in the prevalence of obesity but also a widening of the difference in the prevalence of obesity between the low and high adolescent SES categories (Fig. 1).

\section{Correlates of obesity}

Given the significant differences in the prevalence of obesity between the low- and high-SES categories of adolescents in 2018, obesity correlates are presented separately for all SES categories (Table 3). In all the cycles of data collection, girls in all SES categories reported having a lower prevalence of obesity than boys. Regardless of the adolescent SES category, the lower odds of obesity were significantly $(p<.05)$ associated with regular WVPA, participation in organized sport, and daily consumption of sweets (Table 3). However, the lowest proportion of participants involved in organized sports $(p<.001)$ and regularly engaging in WVPA is among the low-SES adolescents $(p<.001)$.

Additional analysis confirms a significantly lower prevalence of obesity in adolescents with regular participation in WVPA compared with those with less frequent

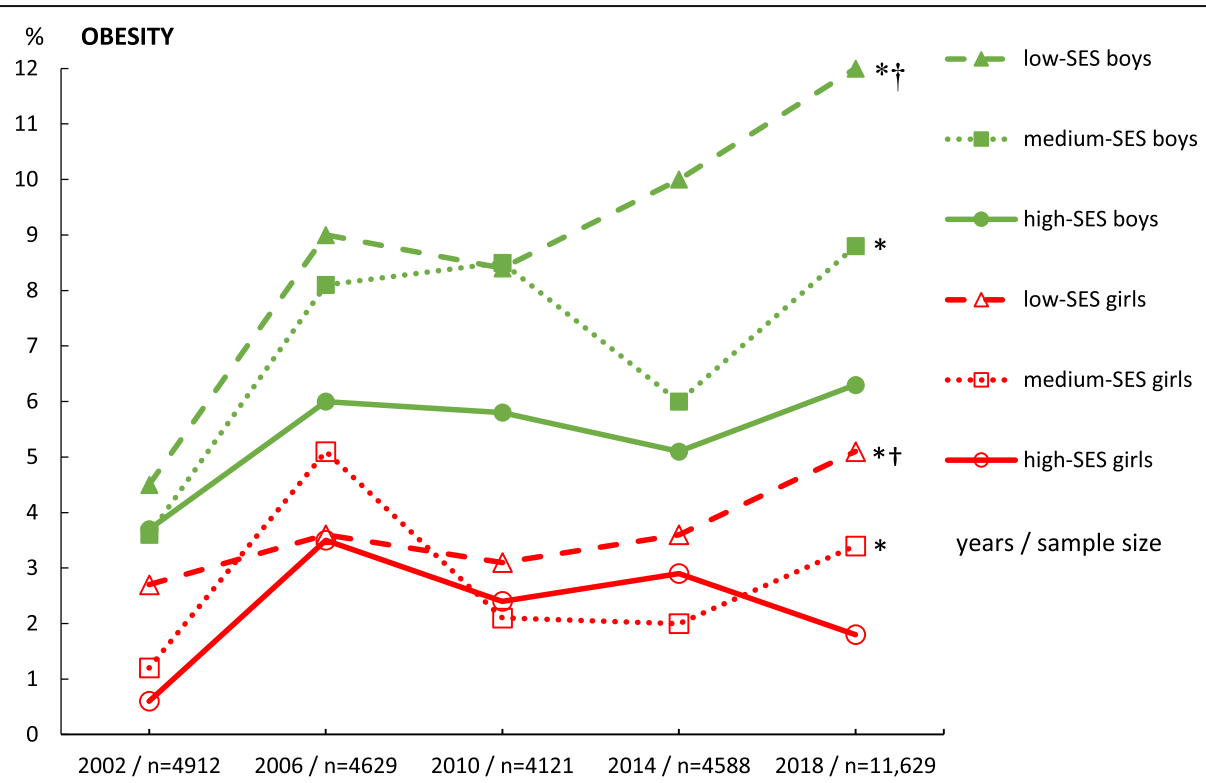

Fig. 1 The changes in the prevalence of obesity in a randomized sample of Czech adolescents aged 11-15 years between 2002 and 2018 . N Number, SES Socioeconomic status, ${ }^{*}$ chi-square tests differences $(p<.05)$ in the prevalence of obesity between 2002 and 2018 , tchi-square tests differences $(p<.05)$ in the prevalence of obesity between low- and high-SES categories of boys and girls separately in 2018 
Table 2 Prevalence of obesity $(\%,(95 \%$ Cl)) in adolescents by gender and SES between 2002 and 2018, HBSC study, Czechia

\begin{tabular}{|c|c|c|c|c|c|c|}
\hline \multicolumn{7}{|l|}{ Obesity } \\
\hline & Year & 2002 & 2006 & 2010 & 2014 & 2018 \\
\hline \multicolumn{7}{|l|}{ Boys } \\
\hline Low SES & & $\begin{array}{l}4.5 \\
(3.0-6.0)\end{array}$ & $\begin{array}{l}9.0 \\
(6.7- \\
11.3)\end{array}$ & $\begin{array}{l}8.4 \\
(5.0- \\
11.8)\end{array}$ & $\begin{array}{l}10.0 \\
\left(7.8^{-}\right. \\
12.2)\end{array}$ & $\begin{array}{l}12.0 \\
(10.2- \\
13.9)\end{array}$ \\
\hline $\begin{array}{l}\text { Medium } \\
\text { SES }\end{array}$ & & $\begin{array}{l}3.6 \\
(2.6-4.6)\end{array}$ & $\begin{array}{l}8.1 \\
(6.6-9.6)\end{array}$ & $\begin{array}{l}8.5 \\
(6.8- \\
10.2)\end{array}$ & $\begin{array}{l}6.0 \\
(4.5-7.5)\end{array}$ & $\begin{array}{l}8.8 \\
(7.7-10.0)\end{array}$ \\
\hline High SES & & $\begin{array}{l}3.7 \\
(1.2-6.2)\end{array}$ & $\begin{array}{l}6.0 \\
(3.8-8.2)\end{array}$ & $\begin{array}{l}5.8 \\
(4.0-7.6)\end{array}$ & $\begin{array}{l}5.1 \\
(3.2-7.0)\end{array}$ & $\begin{array}{l}6.3 \\
(4.6-8.0)\end{array}$ \\
\hline \multicolumn{7}{|l|}{ Girls } \\
\hline LOW SES & & $\begin{array}{l}2.7 \\
(1.7-3.7)\end{array}$ & $\begin{array}{l}3.6 \\
(2.2-5.0)\end{array}$ & $\begin{array}{l}3.1 \\
(1.3-2.9)\end{array}$ & $\begin{array}{l}3.6 \\
(2.4-4.8)\end{array}$ & $\begin{array}{l}5.1 \\
(4.0-6.3)\end{array}$ \\
\hline $\begin{array}{l}\text { Medium } \\
\text { SES }\end{array}$ & & $\begin{array}{l}1.2 \\
(0.04- \\
2.0)\end{array}$ & $\begin{array}{l}5.1 \\
(3.9-6.3)\end{array}$ & $\begin{array}{l}2.1 \\
(1.3-2.9)\end{array}$ & $\begin{array}{l}2.0 \\
(1.2-2.8)\end{array}$ & $\begin{array}{l}3.4 \\
(2.7-4.1)\end{array}$ \\
\hline High SES & & $\begin{array}{l}0.6 \\
(0.01- \\
1.1)\end{array}$ & $\begin{array}{l}3.5 \\
(1.5-5.5)\end{array}$ & $\begin{array}{l}2.4 \\
(1.2-3.6)\end{array}$ & $\begin{array}{l}2.9 \\
(1.4-4.4)\end{array}$ & $\begin{array}{l}1.8 \\
(1.1-2.4)\end{array}$ \\
\hline
\end{tabular}

SES socioeconomic status, Cl 95\% confidence interval

participation (5.0\% vs. $6.8 \%, p<.001)$, active participants in sports compared with non-participating adolescents $(5.0 \%$ vs. $8.1 \%, p<.001)$, and daily consumers of sweets compared with those who consume sweets less often $(3.8 \%$ vs. $6.6, p<.001)$.

At least $60 \mathrm{~min}$ of MVPA daily generally reduce the odds of obesity in adolescents, but the finding was only significant in adolescents from low-SES and high-SES categories. Paradoxically, eating in fast food restaurants more frequently is associated with lower odds of obesity in adolescents (significantly in adolescents from the medium- and high-SES categories) (Table 3).

In the cohort of 11-year-old adolescents, we found the highest prevalence of obesity compared to 13- and 15year-old adolescents ( 11 yrs. $-6.8 \%, 13$ yrs. $-5.9 \%$, and 15 yrs. $-5.6 \%$ ), with the difference being significant between the cohorts of 11- and 15-year-old adolescents $(p<.05)$. In adolescents with at least two hours of ST daily on school/weekend days we revealed a significantly higher prevalence of obesity than in adolescents with less than two hours of ST per day $(6.4 \% / 6.3 \%$ vs. $3.4 \% /$ $3.5 \% p<.001)$. However, in the case of the SES categorization of adolescents, non-excessive ST at weekends is significantly associated with lower odds of the occurrence of obesity only in adolescents from the medium-SES category (Table 3). In adolescents who reported not getting enough sleep on school/weekend days, we found a significantly higher prevalence of obesity than among adolescents meeting the sleep recommendation $(5.5 \% / 5.9 \%$ vs. $6.9 \% / 9.5 \% p<.01)$. A lack of sleep at weekends was significantly associated with higher odds of obesity in adolescents from the mediumand high-SES categories.

\section{Discussion}

The key findings of the trend analysis between 2002 and 2018 include the revelation of an 'up-stairs' effect in the prevalence of obesity in all adolescents except for girls from the high-SES category and increasing differences in the prevalence of obesity between gender-separated lowand high-SES categories of adolescents.

Czechia has undergone rapid economic development and is one of the most economically developed countries in Central and Eastern Europe [26, 45]. This rapid economic development was reflected in the growth of families with high SES after 2010.

However, as in high- economic developed countries, rapid economic development is not always accompanied by positive health development of adolescents in all SES categories. It turns out that Czechia is repeating a similar development in child and adolescent obesity to economically more advanced countries (e.g. Australia, England, France, Germany, Netherlands, and the USA) 10-15 years ago, where the increase in obesity reached a plateau, with a subsequent increase in obesity among low-SES adolescents [7, 63].

After a sharp increase in obesity among Czech adolescents between 2002 and 2006, a number of national health-related and sports programmes (such as "The Olympic Flag of Versatility", "Fruit and Vegetables in Schools", and "Milk to Schools") were introduced for children and adolescents with support from the Ministry of Education, Youth, and Sports [27]. A new compulsory subject called "Health Education" was also established at primary schools. This course focuses on healthy eating habits, non-risky behaviour (avoidance of drug use and smoking) and nature and environmental friendliness. These health-promoting activities may have contributed to the stabilization (plateau) of the prevalence of overweight/obesity among adolescents between 2006 and 2014.

However, following the reduction of nationwide financial support for some national programmes between 2013 and 2015 due to different government priorities, a rebound of overweight/obesity among adolescents was registered in the 2018 national data collection. The subsequent increase in overweight/obesity is most pronounced in adolescents with a low-SES background. The possible subsequent effect of national health and sport programmes is most noticeable in adolescents from high-SES families. In addition, significantly higher odds of obesity in the age categories of 11 and 13 years from low-SES families than among 15-year-olds indicated an expected rise in obesity in older low-SES adolescents in the near future. The trend patterns of excessive body weight, especially obesity in adolescents with a low-SES 
Table 3 Correlates ${ }^{\#}$ of obesity in randomized sample of Czech adolescents in relation to SES: HBSC survey in 2018

\begin{tabular}{|c|c|c|c|c|c|c|c|c|c|}
\hline & & & & & Obesity & & & & \\
\hline & & Low & SES & & Medium & SES & & High & SES \\
\hline & & & $95 \% \mathrm{Cl}$ & & & $95 \% \mathrm{Cl}$ & & & $95 \% \mathrm{Cl}$ \\
\hline & $\%^{\mathrm{a}}$ & OR & lower-upper & $\%^{\mathrm{a}}$ & OR & lower-upper & $\%^{\mathrm{a}}$ & OR & lower-upper \\
\hline Gender & & & & & & & & & \\
\hline Girls & 5.1 & Ref. & & 3.4 & Ref. & & 1.8 & Ref. & \\
\hline Boys & 12.0 & $2.11^{\ddagger}$ & $1.70-2.61$ & 8.8 & $2.29^{\ddagger}$ & $1.93-2.72$ & 6.3 & $2.39^{\ddagger}$ & $1.89-3.03$ \\
\hline Age Category & & & & & & & & & \\
\hline 15 years & 8.7 & Ref. & & 5.5 & Ref. & & 3.3 & Ref. & \\
\hline 13 years & 7.2 & $1.38^{*}$ & $1.07-1.76$ & 6.7 & $1.35^{\dagger}$ & $1.11-1.63$ & 3.8 & 1.20 & $0.93-1.55$ \\
\hline 11 years & 9.0 & $1.39 *$ & $1.06-1.81$ & 6.2 & 1.17 & $0.95-1.46$ & 5.4 & 1.18 & $0.88-1.58$ \\
\hline 60 min of MVPA & & & & & & & & & \\
\hline 0-6 days & 8.8 & Ref. & & 6.2 & Ref. & & 4.7 & Ref. & \\
\hline 7 days & 5.5 & $0.67^{*}$ & $0.47-0.96$ & 5.8 & 0.98 & $0.77-1.24$ & 2.1 & $0.63^{+}$ & $0.46-0.86$ \\
\hline Weekly vigorous PA & & & & & & & & & \\
\hline$<4$ times a week & 9.1 & Ref. & & 6.7 & Ref. & & 4.6 & Ref. & \\
\hline$\geq 4$ times a week & 6.7 & $0.73^{*}$ & $0.57-0.93$ & 5.3 & $0.76^{\dagger}$ & $0.63-0.91$ & 3.6 & $0.78^{*}$ & $0.62-0.99$ \\
\hline Participation in sport & & & & & & & & & \\
\hline Inactive (no participation) & 9.9 & Ref. & & 7.4 & Ref. & & 5.6 & Ref. & \\
\hline Team and/or individual & 7.0 & $0.66^{\ddagger}$ & $0.53-0.81$ & 4.8 & $0.69^{\ddagger}$ & $0.58-0.82$ & 3.5 & $0.75^{*}$ & $0.58-0.96$ \\
\hline Screen time on weekdays & & & & & & & & & \\
\hline$\geq 2 \mathrm{~h}$ per weekday & 8.6 & Ref. & & 6.5 & Ref. & & 4.3 & Ref. & \\
\hline$<2 \mathrm{~h}$ per weekday & 4.9 & 0.91 & $0.59-1.39$ & 2.9 & $0.47^{\ddagger}$ & $0.32-0.68$ & 2.0 & 0.70 & $0.43-1.12$ \\
\hline Breakfast on weekdays & & & & & & & & & \\
\hline less than daily & 8.8 & Ref. & & 7.4 & Ref. & & 4.3 & Ref. & \\
\hline daily & 7.6 & 0.84 & $0.68-1.05$ & 5.1 & $0.81^{*}$ & $0.68-0.96$ & 3.9 & 1.07 & $0.85-1.35$ \\
\hline Consumption of sweets & & & & & & & & & \\
\hline less than daily & 8.9 & Ref. & & 6.5 & Ref. & & 4.6 & Ref. & \\
\hline daily & 5.4 & $0.58^{\ddagger}$ & $0.44-0.78$ & 4.1 & $0.53^{\ddagger}$ & $0.42-0.67$ & 2.0 & $0.58^{\neq}$ & $0.42-0.79$ \\
\hline Eating fast food & & & & & & & & & \\
\hline less often & 8.4 & Ref. & & 6.3 & Ref. & & 4.3 & Ref. & \\
\hline at least twice a month & 8.0 & 0.81 & $0.60-1.09$ & 5.3 & $0.77^{*}$ & $0.61-0.97$ & 3.3 & $0.57^{\ddagger}$ & $0.43-0.77$ \\
\hline Sleep time at weekends & & & & & & & & & \\
\hline enough sleep & 7.9 & Ref. & & 5.9 & Ref. & & 4.4 & Ref. & \\
\hline not enough sleep & 14.0 & 1.15 & $0.87-1.53$ & 8.9 & $1.33^{*}$ & $1.05-1.69$ & 5.5 & $1.48^{*}$ & $1.09-2.00$ \\
\hline too much sleep & 6.0 & 0.79 & $0.61-1.03$ & 4.8 & 0.82 & $0.67-1.01$ & 3.0 & 0.89 & $0.67-1.17$ \\
\hline
\end{tabular}

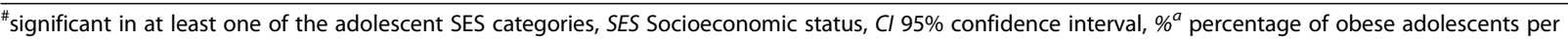
independent variable stratified by SES, OR odds ratio (logistic regression) of being obese in SES separately conducted analysis, Ref. Reference group, $P A$ physical activity, MVPA moderate-to-vigorous physical activity, ${ }^{*} p<.05,{ }^{\dagger} p<.005,{ }^{\ddagger} p<.001$ Significant associations $(p<.05)$ are in bold

background and in the youngest age category examined between 2002 and 2018, indicate an urgent need for improvement. An international comparison of obesity changes between 2002 and 2014 across 27 European countries revealed that most market-driven obesity in Eastern European countries, where the levels of obesity were relatively low in 2002 and in adolescents with a low-SES background (6).
Special attention is therefore paid to the subsequent analyses of obesity correlates in adolescents from various SES backgrounds. Despite the differences in SES, three correlates of energy balance-related behaviours were identified as being associated with significantly lower rates of obesity in all SES groups of adolescents: i) regular WVPA ( $\geq 4$ times a week), ii) active participation in sport, and iii) daily consumption of sweets. Moreover, in 
adolescents from low- and high-SES families, engagement in MVPA for at least $60 \mathrm{~min}$ a day also significantly reduces the risk of obesity. In adolescence, behaviour associated with more pronounced energy expenditure (PA of at least moderate intensity, participation in sport) appears to have a stronger anti-obesity effect than the absence of unhealthy eating habits. However, the energy expenditure required for adolescents must also include the energy required for bodily growth and development. Unlike other studies [64-66], more frequent eating (at least twice a month) in fast food restaurants in Czech adolescents with medium and high SES was associated with a significantly lower risk of obesity than in adolescents with lower rates of eating in fast food restaurants. On the other hand, regular breakfast is, in line with Marlatt et al. [66], associated with lower rates of obesity. These eating patterns are "more typical" for adolescents who regularly participate in sports than for non-participating adolescents. The participation of 11-15-year-old adolescents in sport was related to more frequent eating at fast food restaurants but less frequent snacking in front of the computer and intake of crisps than in non-sporting participants [67]. In addition, in the context of TV, it has been found that adolescents who watched TV for a longer time were more likely to consume sweets and soft drinks daily and less likely to consume fruit and vegetables [56]. However, a more significant obesity-related problem can occur when an adolescent ceases to participate in sports or is not regularly involved in MVPA and does not change his or her eating habits, because unhealthy eating habits adopted in adolescence tend to persist into adulthood and represent a crucial factor in the development of obesity [68-70].

Another explanation for the results that the daily consumption of sweets and eating more frequently in fast food restaurants are related to a lower likelihood of the prevalence of obesity is that non-obese adolescents do not have to care about unhealthy eating habits as much as their obese classmates, as evidenced by previous findings [71, 72]. Better eating habits in the obese category may have been influenced by the "social desirability" factor in addressing dietary habits in the HBSC questionnaire [73]. Undervaluation of responses to unhealthy and socially undesirable foods has proved to be commonplace in questionnaire surveys of overweight and obese participants [74]. The results could also be influenced by the current tendency among overweight or obese adolescents to reduce weight [75]. Because HBSC is cross sectional it is plausible that obese adolescents may be engaging in dietary restriction/healthier dietary habits at the time of the survey.

Excessive body weight is not only associated with long-term cardiovascular and metabolic health complications [10], but also with social and psychosomatic complications [71, 76]. Overweight/obese 11-to-15-yearold girls spend less time with friends after school, and overweight/obese boys report less frequent ecommunication compared to normal-weight adolescents. In addition, the overweight/obese weight status of adolescents is associated with not perceiving a best friend as a confidant [76]. This finding is perhaps also one of the reasons why there are more individuals with normal body weight among the participants in organized team or individual sports. In addition, adolescents from low-SES backgrounds have been significantly more likely to fall behind their peers in terms of life satisfaction [71]. In addition to the financial and logistical demands of adolescents' participation in organized leisure-time sport, this finding may contribute to explaining why the lowest proportion of participants in organized sport and regularly engaging in WVPA is among adolescents with low SES.

Although the lowest proportion of participants in sports and regular WVPA implementation is among the low-SES adolescents, at least 60 min of any MVPA daily can assist in reducing obesity. Therefore, in addition to sport, it is necessary to support and create the conditions for daily implementation of MVPA in all children and adolescents, regardless of the SES category. Improving public open spaces in low-SES areas by installing play spaces for recreational PA [77] or expanding school-related PA (including active recess, physical education lessons $[78,79]$ and after-school nursery [80]) has an impact on increasing day-to-day PA [80] and reducing children's obesity [80, 81].

Short sleep duration is generally associated with increased obesity in European adolescents [82] as well as in adolescents from Canada and the United States [83, 84]. In addition, a positive relationship between shorter sleep duration and obesity appears to be related to both sides of energy balance-related behaviours as a result of a combination of increased food intake and more sedentary habits [82]. However, in our study, short sleep duration at weekends is associated with a significantly higher risk of obesity only in adolescents from medium and high SES backgrounds. A higher prevalence of obesity also appears to be related to the environments that children and adolescents reside in and in the neighbourhood of the schools they attend [65]. Fast food restaurants are more frequently present in low-SES neighbourhoods $[19,65]$. The availability of fast food restaurants near the place of residence or schools is associated with lower consumption of fruits and vegetables, higher consumption of soft drinks, and increased odds of childhood obesity being diagnosed [65].

\section{Strengths and limitations}

The large sample size, with high response rates in all the survey cycles, strict adherence to the international 
standardized questionnaire and research protocol, and the same well-trained research team responsible for data collection are major strengths of this study.

The primary limitation of this study is that the data is based on self-reported assessment. However, the selfreported measures of body weight and height have been validated, and other studies have revealed high correlations between self-reported and laboratory measurements of BMI, making it suitable for epidemiological studies to identify excessive body weight in children and adolescents [36]. Although every attempt was made to minimize bias, the self-reported measures applied in this study are subject to recall and social desirability bias, which may have affected the responses. The crosssectional design of this study does not allow us to interpret the results on the relationship between responses and explanatory variables causally. However, previous longitudinal studies point to the beneficial effects of additional school physical activity on reducing obesity in school-age children $[80,81]$.

\section{Conclusions}

The results of this study pointed out the rising trends of excessive body weight (obesity and overweight), especially in adolescents from low-SES families. Additionally, significantly higher odds of obesity in 11- and 13-yearold adolescents from low-SES families, compared with their peers aged 15, indicated an expectable rise in obesity in older low-SES adolescents in the near future. It seems that association energy expenditure behaviours (participation in individual or team sports, regular weekly vigorous PA, and daily moderate-to-vigorous PA) with weight status in adolescents are stronger than is the case for unhealthy eating habits (daily consumption of sweets or occasional meals at fast food restaurants). We highlight the importance of prevention and the need for more effective strategies/programmes to prevent excessive body weight in children and adolescents with a lowSES background.

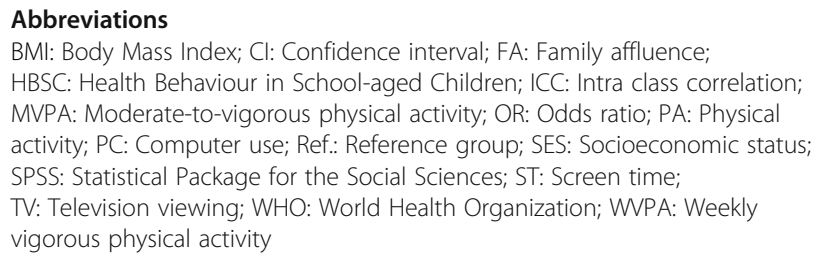

\section{Acknowledgements}

The authors greatly thank all the adolescents for participating in each data collection cycle. Special thanks go to the school management members who helped facilitate the research.

\section{Authors' contributions}

ES conceptualized and designed the study, drafted the initial manuscript, and coordinated the writing of the manuscript. PB, VJrH, MK, ZP, JP, ES, DS, $\mathrm{JV}$, and TH prepared the national research protocol survey and participated in the data collection. DS, PB, VJrH, ZP, and ES carried out the data analysis and interpreted the results. All the authors critically read the initial manuscript, commented on all parts of the text, and approved the final version of the manuscript.

\section{Funding}

This study was supported by research grants from the Czech Science Foundation (reg. No. 17-12579S), the European Regional Development FundProject (reg. No. CZ.02.1.01/0.0/0.0/16_025/0007294), the Technology Agency of the Czech Republic (ÉTA reg. No. TL01000335), and the Ministry of Education, Youth, and Sports (reg. No. LTT18020). The funders had no role in the study design, analysis of the data, decision to publish, or preparation of the study. The funders support nationwide data collection in each cycle of the HBSC cross-sectional study.

\section{Availability of data and materials}

The datasets analysed during the current study are not publicly available because of the rules for funded projects but are available from the corresponding author ES upon reasonable request.

\section{Ethics approval and consent to participate}

The Institutional Research Ethics Committee of the Faculty of Physical Culture, Palacký University Olomouc, approved the design of the study, the course of preparation and execution of the research, an opt-out method for collecting parental consent, and the processing of the data on 4th March 2016, with the reference no. 9/2016. All the adolescents, teachers, and school management members received detailed information on the survey design and data collection plan at a meeting at each of the participating schools. The adolescents' parents were informed about the survey and its design and content via the school management in advance and could withdraw their child if they wished. They received the information on the goal, content and course of the research, as well as possibility of opting their child out during parent-teacher conferences or, if absent, via e-mail. Written informed consent was obtained from all participants. In each cycle of data collection, the participation of adolescents was voluntary and without any financial incentives.

\section{Competing interests}

The authors declare that they have no conflict of interest.

\section{Author details}

${ }^{1}$ Faculty of Physical Culture, Institute of Active Lifestyle, Palacký University Olomouc, 77111 Olomouc, Czech Republic. ${ }^{2}$ Faculty of Physical Culture, Department of Recreation and Leisure Studies, Palacký University Olomouc, 77111 Olomouc, Czech Republic. ${ }^{3}$ Faculty of Physical Culture, Department of Social Sciences in Kinanthropology, Palacký University Olomouc, 77111 Olomouc, Czech Republic.

Received: 6 June 2019 Accepted: 7 February 2020

Published online: 13 February 2020

\section{References}

1. Ford ND, Patel SA, Narayan KMV. Obesity in low- and middle-income countries: burden, drivers, and emerging challenges. Annu Rev Public Health. 2017;38:145-64.

2. Hruby A, Hu FB. The epidemiology of obesity: a big picture. Pharmacoeconomic. 2015;33(7):673-89.

3. Mitchell N, Catenacci V, Wyatt HR, Hill JO. Obesity: overview of an epidemic. Psychiatr Clin North Am. 2011;34(4):717-32.

4. Ng M, Fleming T, Robinson M, Thomson B, Graetz N, Margono C, et al. Global, regional, and national prevalence of overweight and obesity in children and adults during 1980-2013: a systematic analysis for the global burden of disease study 2013. Lancet. 2014;384(9945):766-81.

5. Seidel JC, Halberstadt J. The global burden of obesity and the challenges of prevention. Ann Nutr Metab. 2015;66(Suppl 2):7-12.

6. Inchley J, Currie D, Jewell J, Breda J, Barnekow V. Adolescent obesity and related behaviours: trends and inequalities in the WHO European Region, 2002-2014. WHO Reg Off Eur 2017. http://www.euro.who.int/_data/assets/ 
pdf_file/0019/339211/WHO_ObesityReport_2017_v3.pdf?ua=1. Accessed 23 May 2019.

7. Frederick CB, Snellman K, Putnam RD. Increasing socioeconomic disparities in adolescent obesity. Proc Nation Acad Sci Unit Stat Am. 2014;111(4):1338-42.

8. Hamřík Z, Sigmundová D, Pavelka J, Kalman M, Sigmund E. Trends in overweight and obesity in Czech schoolchildren from 1998 to 2014. Cent Eur J Public Health. 2017;25(Suppl 1):10-4.

9. Hardy LL, Mihrshahi S, Gale J, Drayton BA, Bauman A, Mitchell J. 30-year trends in overweight, obesity and waist-to-height ratio by socioeconomic status in Australian children, 1985 to 2015. Int J Obes. 2017;41(1):76-82.

10. Kelly A, Barlow SE, Rao G, Inge TH, Hayman LL, Steinberger J, et al. Severe obesity in children and adolescents: identification, associated health risks, and treatment approaches: a scientific statement from the American Heart Association. Circulation. 2013;128(15):1689-712.

11. Cawley J, Meyerhoefer C. The medical care costs of obesity: an instrumental variables approach. J Health Econ. 2012;31(1):219-30.

12. Tremmel M, Gerdthem UG, Nilsson PM, Saha S. Economic burden of obesity: a systematic literature review. Int J Environ Res Public Health. 2017;14(4):E435.

13. Dumuid D, Olds T, Lewis LK, Martin-Fernández JA, Barreirea T, Broyles S, et al. The adiposity of children is associated with their lifestyle behaviours: a cluster analysis of school-aged children from 12 nations. Pediatr Obes. 2016; 13(2):111-9.

14. Huang TT, Drewnowski A, Kumanyika SK, Glass TA. A systems-oriented multilevel framework for addressing obesity in the $21^{\text {st }}$ century. Prev Chronic Dis. 2009;6(3):A82.

15. Ren H, Zhou Z, Liu W, Wang X, Yin Z. Excessive homework, inadequate sleep, physical inactivity and screen viewing are major contributors to high paediatric obesity. Acta Paediatr. 2016;106(1):120-7.

16. Wilkie HJ, Standage M, Gillison FB, Cumming SP, Katzmarzyk PT. Multiple lifestyle behaviours and overweight and obesity among children aged 9-11 years: result from the UK site of the international study of childhood obesity. Lifestyle Environ BMJ Open. 2016;6(2):e010677.

17. Bleich SN, Vercammen KA. The negative impact of sugar-sweetened beverages on children's health: an update of the literature. BMC Obes. 2018;5:6.

18. Sigmund E, Badura P, Sigmundová D, Voráčová J, Zacpal J, Kalman M, et al. Trends and correlates of overweight/obesity in Czech adolescents in relation to family socioeconomic status over a 12-year study period (20022014). BMC Public Health. 2018;18(1):122.

19. Voráčová J, Sigmund E, Sigmundová D, Kalman M. Family affluence and the eating habits of 11- to 15-year-old Czech adolescents: HBSC 2002 and 2014. Int J Environ Res Public Health. 2016;13(10):E1034.

20. Nobari TZ, Whaley SE, Prelip ML, Crespi CM, Wang MC. Trends in socioeconomic disparities in obesity prevalence among low-income children aged 2-4 years in Los Angeles county, 2003-2014. Child Obes. 2018; 14(4):248-58.

21. Bann D, Johnson W, Li L, Kun D, Hardy R. Socioeconomic inequalities in childhood and adolescent body-mass index, weight, and height from 1953 to 2015: an analysis of four longitudinal, observational, British birth cohort studies. Lancet Public Health. 2018;3(4):e194-203.

22. Newton S, Braithwaite D, Akinyemiju TF. Socio-economic status over the life course and obesity. Systematic review and meta-analysis. PLoS One. 2017; 12(5):e0177151.

23. Bucksch J, Sigmundova D, Hamrik Z, Troped PJ, Melkevik O, Ahluwalia N, et al. International trends in adolescent screen-time behaviors from 2002 to 2010. J Adolesc Health. 2016;58(4):417-25.

24. Kalman M, Inchley J, Sigmundova D, lannotti RJ, Tynjälä JA, Hamrik Z, et al. Secular trends in moderate-to-vigorous physical activity in 32 countries from 2002 to 2010: a cross-national perspective. Eur J Pub Health. 2015; 25(Suppl 2):37-40.

25. lannotti RJ, Wang J. Trends in physical activity, sedentary behavior, diet, and BMl among US adolescents, 2001-2009. Pediatrics. 2013;132(4):606-14.

26. OECD Data. Czech Republic - Selected indicators for Czech Republic. Available onile: https://data.oecd.org/czech-republic.htm. Accessed 24 May 2019.

27. Research \& Development MSMT. Ministry of Education, Youth and Sports The Central Administrative Office Responsible for Research and Development. Available online: http://www.msmt.cz/research-anddevelopment-1. Accessed 24 May 2019.

28. Currie C, Nic Gabhainn S, Godeau E. The health behaviour in school-aged children: WHO collaborative cross-national (HBSC) study: origins, concept, history and development 1982-2008. Int J Public Health. 2009;54(Suppl 2): $131-9$.
29. Roberts C, Freeman J, Samdal O, Schnohr CW, Looze M, Nic Gabhainn S, et al. The health behaviour in school-aged children (HBSC) study: methodological developments and current tensions. Int J Public Health. 2009:54(Suppl 2):140-50.

30. de Onis M, Lobstein, T. Defining obesity risk status in the general childhood population: which cut-offs should we use? Int J Pediatr Obes 2010;5(6):458-0.

31. de Onis M, Onyango AW, Borghi E, Siyam A, Nishida C, Siekmann J. Development of a WHO growth reference for school-aged children and adolescents. Bull World Health Organ. 2007;85(9):660-7.

32. Bilík J, editor. Demographic yearbook of districts of the Czech Republic 2008-2017. 1st ed. Prague: Czech Statistical Office; 2018. p. 1-145.

33. HBSC International Research Protocol. Health Behaviour in School-Aged Children - Survey Methods. 2019. http://www.hbsc.org/methods/index.html. Accessed 24 May 2019.

34. Chan NPT, Choi KC, Nelson EAS, Sung RYT, Chan JCN, Kong APS. Selfreported body weight and height: an assessment tool for identifying children with overweight/obesity status and cardiometabolic risk factors clustering. Matern Child Health J. 2013;17(2):282-91.

35. Fonseca H, Silva AM, Matos MG, Esteves I, Costa P, Guerra A, et al. Validity of BMI based on self-reported weight and height in adolescents. Acta Paediatr. 2010;99(1):83-8.

36. Aasvee K, Rasmussen M, Kelly C, Kurvinen E, Giacchi MV, Ahluwalia N. Validity of self-reported height and weight for estimating prevalence of overweight among Estonian adolescents: the health behaviour in schoolaged children study. BMC Res Notes. 2015;8:606.

37. Ahluwalia N, Dalmasso P, Rasmussen M, Lipsky L, Currie C, Haug E, et al. Trends in overweight prevalence among 11-, 13- and 15-years-olds in 25 countries in Europe, Canada and USA from 2002 to 2010. Eur J Pub Health. 2015;25(Suppl 2):28-32.

38. Currie C, Molcho M, Boyce W, Holstein B, Torsheim T, Richter M. Researching health inequalities in adolescents: the development of the health behaviour in school-aged children (hbsc) family affluence scale. Soc Sci Med. 2008;66: 1429-36.

39. Currie C, Inchley J, Molcho M, Lenzi M, Veselak Z, Wild F. Health Behaviour in School-Aged Children (HBSC) Study Protocol: Background, Methodology and Mandatory Items for the 2013/2014 Survey, 1st ed. CAHRU: St. Andrews, United Kingdom. 2014:1-48.

40. Andersen A, Krølner R, Currie C, Dallago L, Due P, Richter M, et al. High agreement on family affluence between children's and parents' reports: international study of 11-year-old children. J Epidemiol Community Health. 2008;62:1092-4

41. Boyce W, Torsheim T, Currie C, Zambon A. The family affluence scale as a measure of national wealth: validation of an adolescent self-reported measure. Soc Indic Res. 2006;78:473-7.

42. Hartley JEK, Levin K, Currie C. A new version of the HBSC family affluence scale - FAS III: Scottish qualitative findings from the international FAS development study. Child Indicat Res. 2015;9:233-45.

43. Liu Y, Wang M, Villberg J, Torsheim T, Tynjälä J, Lv Y, et al. Reliability and validity of family affluence scale (FAS II) among adolescents in Beijing, China. Child Indicat Res. 2012;5:235-51.

44. Molcho M, Gabhainn SN, Kelleher CC. Assessing the use of the family affluence scale (fas) among Irish schoolchildren. Ir Med J. 2007;100(Suppl 8):37-9.

45. Hobza V, Hamrik Z, Bucksch J, De Clerg B. The family affluence scale as an indicator for socioeconomic status: validation on regional income differences in the Czech Republic. Int J Environ Res Public Health. 2017; 14(12):E1540.

46. Janssen I, LeBlanc AG. Systematic review of the health benefits of physical activity and fitness in school-aged children and youth. Int J Behav Nutr Phys Act. 2010:12:10

47. Inchley J, Currie D, Young T, Samdal O, Torsheim T, Augustson L, et al. Growing up unequal: gender and socioeconomic differences in young people's health and well-being. Health Behaviour in School-Aged children (HBSC) Study: International report from the 2013/2014 survey. Health Policy for children and adolescents, No. 7. Copenhagen: WHO Regional Office for Europe 2016. http://www.euro.who.int/_data/assets/pdf_file/0003/303438/ HSBC-No.7-Growing-up-unequal-Full-Report.pdf Accessed on 24 May 2019

48. Prochaska JJ, Sallis JF, Long B. A physical activity screening measure for use with adolescents in primary care. Arch Pediatr Adolesc Med. 2001;155(5):554-9.

49. Ridgers ND, Timperio A, Crawford D, Salmon J. Validity of a brief self-report instrument for assessing compliance with physical activity quidelines amongst adolescents. J Sci Med Sport. 2012;15(2):136-41. 
50. Bobakova D, Hamrik Z, Badura P, Sigmundova D, Nalecz H, Kalman M. Test-retest reliability of selected physical activity and sedentary behavior HBSC items in the Czech Republic, Slovakia and Poland. Int J Public Health. 2015;60(1):59-67.

51. Liu Y, Wang M, Tynjälä J, LV Y, Villberg J, Zhang Z, et al. Test-retest reliability of selected items of health behaviour in school-aged children (HBSC) survey questionnaire in Beijing, China. BMC Med Res Methodol. 2010;10:73.

52. Badura P, Sigmund E, Geckova AM, Sigmundova D, Sirucek J, van Dijk JP, et al. Is participation in organized leisure-time activity associated with school performance in adolescence? PLoS One. 2016;11(4):e0153276.

53. Bosakova L, Kolarcik P, Bobakova D, Sulcova M, Van Dijk JP, Reijneveld SA, et al. Test-retest reliability of the scale of participation in organized activities among adolescents in the Czech Republic and Slovakia. Int J Public Health. 2016:61(3):329-36.

54. Sigmundová D, Sigmund E, Bucksch J, Bad’ura P, Kalman M, Hamř́k Z. Trends in screen time behaviours in Czech schoolchildren between 2002 and 2014: HBSC study. Cent Eur J Public Health. 2017;25(Suppl 1):15-20.

55. Schmitz KH, Harnack L, Fulton JE, DRJ J, Gao S, Lytle AL, et al. Reliability and validity of a brief questionnaire to assess television viewing and computer use by middle school children. J Sch Health. 2004;74(9):370-7.

56. Vereecken CA, Todd J, Roberts C, Mulvihill C, Maes L. Television viewing behaviour and associations with food habits in different countries. Public Health Nutr. 2006;9(2):244-50.

57. Rey-López JP, Vicente-Rodriguez G, Ortega FB, Ruiz JR, Martinez-Gómez D, De Henauw S, et al. Sedentary patterns and media availability in European adolescents: the HELENA study. Prev Med. 2010;51(1):50-5.

58. Salmon J, Campbell KJ, Crawford DA. Television viewing habits associated with obesity risk factors: a survey of Melbourne schoolchildren. Med J Aust. 2006;184(2):64-7.

59. Tremblay MS, LeBlanc AG, Janssen I, Kho ME, Hicks A, Murumets K, et al. Canadian sedentary behavior guidelines for children and youth. Appl Physiol Nutr Metab. 2011;36(1):59-64.

60. Vereecken C, Pedersen TP, Ojala K, Krølner R, Dzielska A, Ahluwalia N, et al. Fruit and vegetable consumption trends among adolescents from 2002 to 2010 in 33 countries. Eur J Pub Health. 2015;25(Suppl 2):16-9.

61. Leger D, Beck F, Richard JB, Godeau E. Total sleep time severely drops during adolescence. PLoS One. 2012;7(10):e45204.

62. Paruthi S, Brooks ப, D'Ambrosio C, Hall WA, Kotagal S, Lloyd RM, et al. Recommended amount of sleep for pediatric populations: a consensus statement of the American Academy of sleep medicine. J Clin Sleep Med. 2016;12(6):785-6.

63. Wabitsch M, Moss A, Kromeyer-Hauschild K. Unexpected plateauing of childhood obesity rates in developed countries. BMC Med. 2014;12:17.

64. Braithwaite I, Stewart AW, Hancox RJ, Beasley R, Murphy R, Mitchel EA, et al. Fast-food consumption and body mass index in children and adolescents: an international cross-sectional study. BMJ Open. 2014;4(12):e005813.

65. Hamano T, Li X, Sundquist J, Sundquist K. Association between childhood obesity and neighbourhood accessibility to fast-food outlets: a nationwide 6-year follow-up study of 944,487 children. Obes Facts. 2017;10(6):559-68.

66. Marlatt KL, Farbakhsh K, Dengel DR, Lytle LA. Breakfast and fast food consumption are associated with selected biomarkers in adolescents. Prev Med Rep. 2015;3:49-52.

67. Voráčová J, Badura P, Hamrik Z, Holubčíková J, Sigmund E. Unhealthy eating habits and participation in organized leisure-time activities in Czech adolescents. Eur J Pediatr. 2018:177(10):1505-13.

68. Emmett PM, Jones LR. Diet, growth, and obesity development throughout childhood in the Avon longitudinal study of parents and children. Nutr Rev. 2015;73(Suppl 3):175-206.

69. León-Muñoz LM, García-Esquinas E, Soler-Vila H, Guallar-Castillón P, Banegas $J R$, Rodríguez-Artalejo F. Unhealthy eating behaviors and weight gain: a prospective study in young and middle-age adults. Obesity (Silver Spring). 2016;24(5):1178-84.

70. Mikkilä V, Räsänen L, Raitakari OT, Pietinen P, Viikari J. Longitudinal changes in diet from childhood into adulthood with respect to risk of cardiovascular diseases. The cardiovascular risk in young Finns study. Eur J Clin Nutr. 2004;58(7):1038-45.

71. Chzhen Y, Moor I, Pickett W, Toczydlowska E, Stevens G. Family affluence and inequality in adolescent health and life satisfaction: Evidence from the HBSC study 2002-2014. Innocenti Working Pap. 2016;2016-10:1-26.

72. Sigmundová D, Sigmund E, Hamrik Z, Kalman M. Trends of overweight and obesity, physical activity and sedentary behaviour in Czech schoolchildren: HBSC study. Eur J Pub Health. 2014;24(2):210-5.

73. Bel-Serrat S, Julian-Almarcegui C, Gonzalez-Gross M, Mouratidou T, Bornhorst C, Grammatikaki E, et al. Correlates of dietary energy misreporting among European adolescents: the healthy lifestyle in Europe by nutrition in adolescence (HELENA) study. Br J Nutr. 2016;115(8):1439-52.

74. Hebert JR, Hurley TG, Peterson KE, Resnicow K, Thompson FE, Yaroch AL, et al. Social desirability trait influences on self-reported dietary measures among diverse participants in a multicenter multiple risk factor trial. J Nutr. 2008;138(1):226-34.

75. Ojala K, Vereecken C, Välimaa R, Currie C, Vilberg J, Tynjälä J, et al. Attemps to lose weight among overweight and non-overweight adolescents: a cross-national survey. Int J Behav Nutr Phys Act. 2007:4:50.

76. Kjelgaard HH, Holstein BE, Due P, Brixval CS, Rasmussen M. Adolescent weight status: association with structural and functional dimensions of social relations. J Adolesc Health. 2017;60(4):460-8.

77. Lal A, Moodie M, Abbott G, Carver A, Salmon J, Giles-Corti B, et al. The impact of a park refurbishment in a low socioeconomic area on physical activity: a cost-effectiveness study. Int J Behav Nutr Phys Act. 2019;16:26.

78. Sigmund E, Sigmundová D, Šnoblová D, Gecková AM. Actitrainerdetermined segmented moderate-to-vigorous physical activity patterns among normal-weight and overweight-to-obese Czech schoolchildren. Eur J Pediatr. 2014;173(3):321-9.

79. Sigmund E, Sigmundová D, Hamrik Z, Gecková AM. Does participation in physical education reduce sedentary behaviour in school and throughout the day among normal-weight and overweight-to-obese Czech children aged 9-11 years? Int J Environ Res Public Health. 2014;11(1):1076-93.

80. Sigmund E, El Ansari W, Sigmundová D. Does school-based physical activity decrease overweight and obesity in children 6-9 years? A two-year nonrandomized longitudinal intervention study in the Czech Republic. BMC Public Health. 2012;12:570.

81. Sigmund E, Sigmundová D. Longitudinal 2-year follow-up on the effect of a non-randomised school-based physical activity intervention on reducing overweight and obesity of Czech children aged 10-12 years. Int J Environ Res Public Health. 2013;10(8):3667-83.

82. Garaulet M, Ortega FB, Ruiz JR, Rey-López JP, Béghin L, Manios Y, et al. Short sleep duration is associated with increased obesity markers in European adolescents: effect of physical activity and dietary habits. The HELENA study. Int J Obes (Lond). 2017;35(10):1308-17.

83. Miller MA, Kruisbrink M, Wallace J, Ji C, Cappuccio FP. Sleep duration and incidence of obesity in infants, children, and adolescents: a systematic review and meta-analysis of prospective studies. Sleep. 2018;41(4):1-19.

84. Sluggett L, Wagner SL, Harris RL. Sleep duration and obesity in children and adolescents. Can J Diabetes. 2019;43(2):146-52.

\section{Publisher's Note}

Springer Nature remains neutral with regard to jurisdictional claims in published maps and institutional affiliations.

Ready to submit your research? Choose BMC and benefit from:

- fast, convenient online submission

- thorough peer review by experienced researchers in your field

- rapid publication on acceptance

- support for research data, including large and complex data types

- gold Open Access which fosters wider collaboration and increased citations

- maximum visibility for your research: over $100 \mathrm{M}$ website views per year

At $\mathrm{BMC}$, research is always in progress.

Learn more biomedcentral.com/submission 